\title{
Cautious expansion in the private sector
}

There were few doctors and nurses among the delegates at the recent conference on private health care organised by the Financial Times. Nor were there any health service administrators or managers to listen to their colleague from Portsmouth describing his district's successful collaboration with the private sector. Their reluctance, presumably the result of the high conference fee, was understandable; but perhaps a pity, because the conference, largely attended by people in business and finance, and by many representatives from private hospitals, yielded some indicators for the future practice of medicine.

In private hospital practice, the outlook predicted by most speakers was of steady but unspectacular growth, with the new aggressive profit making companies drawing well away from the older non-profit making ones. The sharp climb in the numbers insured for private treatment that occurred from 1979 to 1982 has given way to a gentle upward slope. The decline in enthusiasm, which may be reversed by this year's budget with its changes in National Insurance contributions, is accompanied by a more critical attitude on the part of employers towards the cost of group schemes. For their part, insurers will keep a similarly sharp eye on hospital charges and doctors' fees.

The need for cost and quality control was a theme that ran through the conference. Indeed, a speaker from British Airways said that, were the rise in costs per person covered to be maintained at the $20 \%$ experienced between 1983 and 1984 , it might have to be abandoned. Consultants, on the whole, do not charge fees above those prescribed in insurers' policies. The insurers' complaint is that they tend to charge the maximum even when the treatment does not justify it. There was a general feeling that doctors and private hospitals should not be greedy if the growth in private practice is to be maintained. Looking at it from a health service viewpoint, authorities are concerned lest the extent of private facilities is taken into account when revenue allocations are determined.

The belief that private practice will grow has to be tempered by the possibility of a change in government. $\mathrm{Mr}$ Michael Meacher, opposition spokesman on health, was suitably tactful in his address. He did not pledge his party to the prohibition of private practice by health service consultants or even to repeat the attempt to abolish pay beds. But he did say that the Labour party would remove any tax concessions that encourage private practice and would make sure that consultants fulfilled their contractual obligations to the NHS. He referred again to the recent reports of the Audit Commission showing that some health authorities were not receiving the income due to them from patients treated privately in health service hospitals. Mr Meacher claims that the audit confirms suspicions of abuse by some consultants, however few, of their private practice privileges. Mr Kenneth Clarke, the present Minister for Health, who has refused to publish the reports, says that authorities should be more assiduous in tracking down expenditure on private patients. Perhaps they need to be but consultants, too, have a responsibility to keep the rules. Their influence on hospital waiting lists may produce a conflict of interest when they are faced with patients willing to pay for prompt treatment. Although promptness is not the only reason for patients wanting to be treated privately, this potential conflict of interest is all the more reason that in treating private patients consultants should not attract the slightest suspicion.
Mr John Chawner, consultant obstetrician and chairman of the BMA's private practice and professional fees committee, was clearly unhappy at the bad press that his colleagues have been receiving on their conduct of private practice in NHS hospitals. Vigorously repudiating the "false impression" that the recent audit had shown "wholesale fiddling by consult-을 ants," he said that over the years very few had done so and the $\overrightarrow{\bar{c}}$ BMA would not defend them. What had come to light in the audit was the "wholesale disregard" by health authorities of $\frac{\bar{O}}{\circ}$ the proper collection procedures and the fact that private $\overline{\overline{\bar{n}}}$. practice in hospitals was governed by "an incredibly complex $\underset{\Omega}{\Phi}$ ragbag of laws, regulations, guidance notes, health circulars, terms and conditions of employment, local rules, and ${ }_{\vec{\circ}}$ agreements negotiated with the profession." The BMA was. reviewing the rules with the aim of issuing-probably with $\bar{\omega}$ the DHSS-firm guidance. Mr Chawner also reminded his audience of events when the Labour party had been in 3 . power, with private patients "harassed" and health authorities failing to enforce the rules, something which he believed had. contributed to the present disarray:

Mr Clarke, however, also seems to have qualms about the ज़ potential conflict of interest facing consultants because he $\overrightarrow{0}$ said that those who were whole time in the NHS should $\infty$ continue to restrict their earnings from private patients to을 $10 \%$ of their total income. Unlike Mr Chawner, who wanted $\vec{\omega}$ "to see all doctors free to undertake as much private practice $>$ as they wished without restriction," he believes the govern-ㅡㅡ. ment should retain regulatory powers over the quantity and $\vec{\bullet}$ quality of private hospital provision. The minister also o believes that any demand met by private practice enables the NHS to treat its patients more easily. This belief, so often voiced, is far too simple. As was pointed out more than once at the conference, insurance cover for health created new demands that would not become overt, or would be firmly checked, in NHS practice; it is this extra demand that is $\vec{F}$ partly responsible for the rise in insurance costs.

New demands and expectations, or consumerism (another prevailing theme at the conference), are also being experienced? in general practice. Mr Clarke was cautious about the future of private practice in primary care, apart from declaring that any doctor is free to have private patients if he wants to. $\frac{0}{3}$ When, however, the Green Paper on the family practitioner services is eventually published, doctors may find themselves $\frac{0}{3}$ in for a shock. Mr Clarke insisted that payment by vouchers

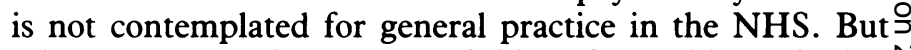
other speakers raised the possibility of portable capitation $N$ fees, which patients would take to the doctor of their choice $\frac{D}{2}$ and could take elsewhere if they were dissatisfied with him.

The difficulty of changing from one family doctor to 0 another is, perhaps, the most common complaint voiced by patients. The government doubtless hopes to build on this expression of consumerism to make general practice more competitive in the belief that competition will control costs and thereby make it easier to extend cash limits to this part of the NHS. The minister was being suitably discreet on this ${ }_{0}^{-}$ occasion, but discussions on the future direction of general $\stackrel{\mathbb{Q}}{\circ}$ practice and the place of private practice in it will, no doubt, $\stackrel{\mathbb{D}}{\stackrel{Q}{\circ}}$ be anything but discreet once the Green Paper is published. Meanwhile the debate on the private and state sectors will be $\delta$ fuelled by a study, Towards a new understanding, just?ํㅡ published by the Nuffield Centre for Health Studies (p 1155), which found that both sectors viewed collaborative arrangements "as an avenue of last resort." 